\title{
Odorant Receptors and Desensitization Proteins Colocalize in Mammalian Sperm
}

\author{
Loren D. Walensky, ${ }^{*}$ A. Jane Roskams, ${ }^{\dagger}$ Robert J. Lefkowitz, ${ }^{\S}$ \\ Solomon H. Snyder, ${ }^{* \neq}$ and Gabriele V. Ronnett ${ }^{\dagger}$ \\ Departments of *Pharmacology and Molecular Sciences, \\ ${ }^{\dagger}$ Neuroscience, and ${ }^{\ddagger}$ Psychiatry and Behaviorial Sciences and \\ Neurology, Johns Hopkins University School of Medicine, Baltimore, \\ Maryland, U.S.A. ${ }^{\text {S} D e p a r t m e n t s ~ o f ~ M e d i c i n e ~ a n d ~ B i o c h e m i s t r y ~ a n d ~}$ \\ the Howard Hughes Medical Institute, Duke University Medical \\ Center, Durham, North Carolina, U.S.A.
}

\begin{abstract}
Background: The identification of transcripts encoding putative olfactory receptors in mammalian germ cells (1) has generated the hypothesis that olfactory receptors may serve a chemosensory role in sperm chemotaxis during fertilization. We have sought to identify and localize these receptors and their regulatory machinery in rat sperm in order to gain further insight into mammalian sperm chemotaxis and odorant receptor physiology.

Materials and Methods: We conducted reverse transcription-polymerase chain reaction (RT-PCR) using degenerate primers directed against sequences conserved across members of the known odorant receptor family to identify transcripts from testis and round spermatids. Western analysis and immunohistochemistry were performed using antibodies raised against two peptide sequences conserved among odorant receptors and using fusion protein antibodies to $G$ protein receptor kinase 3 (GRK3/BARK2) and $\beta$-arrestin2.
\end{abstract}

Results: We detected transcripts encoding putative odorant receptors in both testis and round spermatids of the adult rat. Restriction digests of the PCR products demonstrated the existence of multiple gene products. Two anti-odorant receptor antibodies specifically recognized a $64 \mathrm{kD}$ band in rat sperm preparations by Western blot. The proteins GRK3 and $\beta$-arrestin2, implicated in olfactory desensitization, were detected in sperm cytosolic extracts using Western analysis. Immunohistochemistry colocalized putative odorant receptors, GRK3 and $\beta$-arrestin 2 to elongating spermatids in the testis and to the midpiece of mature sperm. Conclusions: The specific localization of odorant receptors to the respiratory center of mature sperm is consistent with a role for these proteins in transducing chemotactic signals. Based on the colocalization, it is plausible that GRK 3 and $\beta$-arrestin 2 function in sperm to regulate putative chemoreceptor responses.

\section{INTRODUCTION}

Chemoattraction is a common feature of olfaction and sperm-egg interactions. Given the importance of chemosensation in reproductive behavior, a strong conservation may exist in the

Address correspondence and reprint requests to: Solomon H. Snyder, Departments of Neuroscience, Pharmacology and Molecular Science, Psychiatry and Behavioral Sciences, Johns Hopkins University School of Medicine, $725 \mathrm{~N}$. Wolfe Street, Baltimore MD 21205, U.S.A. molecular mechanisms that underly olfaction and gamete chemotaxis. Molecular cloning of putative odorant receptors revealed a large multigene family of seven transmembrane G-protein linked receptors (2). Odorants are likely recognized by specific odorant receptors localized to the cilia at the ends of olfactory neuronal dendrites. Estimates of the number of distinct receptor proteins approach one thousand, consistent with the ability of mammals to differentiate thousands of odorants (3). Sperm-egg chemo- 
taxis has been well documented in invertebrates, where very low concentrations of speract and resact, peptides secreted by sea urchin eggs, attract spermatozoa in a species-specific manner $(4,5)$. The peptides facilitate fertilization by binding to sperm receptors and thereby stimulate motility and respiration (6). Analogous ligandreceptor interactions in vertebrates have not been characterized, although human sperm are attracted by follicular fluid in vitro (7).

For G-protein linked receptors, desensitization of receptor responses plays an important role in signal transduction. The principal mechanism of agonist-specific desensitization appears to involve receptor phosphorylation by G-protein coupled receptor kinases (GRKs) (8). $\beta$ Adrenergic receptor kinase-1 ( $\beta$ ARK1/GRK2) was first identified on the basis of its ability to specifically phosphorylate agonist bound $\beta$-adrenergic receptors $(9,10)$. An additional protein, designated $\beta$-arrestin, binds to the phosphorlyated receptor and prevents its further activation of G-proteins (11). Multiple isoforms of GRK 7 and arrestin $(11,12,13)$ have been described. GRK3 ( $\beta$ ARK2) and $\beta$-arrestin2 were recently localized to the dendritic knobs and cilia of olfactory receptor neurons and have been implicated in agonist-dependent desensitization in olfaction (14). Whereas desensitization has been documented in invertebrate sperm chemotaxis (15, 16), a corresponding process in vertebrates has not been explored.

Initial cloning studies suggested that odorant receptors occurred only in olfactory tissue (2). Recently, Parmentier and colleagues identified putative odorant receptors in dog testis (1) and localized one of these receptors in dog sperm (17). In the present study, we identify odorant receptor transcripts in rat testis and in round spermatids and colocalize putative odorant receptors with specific GRK and $\beta$-arrestin isoforms in mature rat sperm. These results suggest that common mechanisms to detect and modulate chemical signals may exist in the olfactory and reproductive systems.

\section{MATERIALS AND METHODS}

\section{Reverse Transcription-Polymerase Chain Reaction Amplification of Putative Sperm Chemoreceptors}

RNA was prepared from testis and whole brain of 350-g Sprague-Dawley rats using TRIzol reagant
(GIBCO-BRL) and Oligotex poly A selection (Qiagen) according to manufacturer protocols. Round spermatids were purified from adult rat testis according to established procedures (18); the cell pellet was homogenized in guanidinium isothiocyanate and RNA was pelleted through a cesium chloride gradient by centrifuging for 20-22 hr at 35,000 rpm (19). Integrity and quantity of RNA was assessed by absorbance at $260 / 280 \mathrm{~nm}$ and purity confirmed by agarose gel electrophoresis. RNA was subsequently treated with 10 U RNAse-free DNAse (GIBCO-BRL) per $\mu g$ of RNA. Five micrograms of RNA from each source was reverse transcribed (Superscript RT, GIBCO-BRL) using oligo-dT or random primers (Promega). In addition, control reactions were run that excluded enzyme from the reverse transcription (RT) reaction. Polymerase Chain reaction (PCR) was performed on a $1 / 20$ aliquot of the RT reaction mixture for 35 cycles of $94^{\circ} \mathrm{C}$ for 1 $\min , 50^{\circ} \mathrm{C}$ for $1 \mathrm{~min}$ and $72^{\circ} \mathrm{C}$ for $1 \mathrm{~min}$ using TAQ DNA Polymerase (GIBCO-BRL).

Degenerate primers were designed to hybridize to conserved regions of all members of the originally cloned putative odorant receptor family. The primer pairs are as follows:

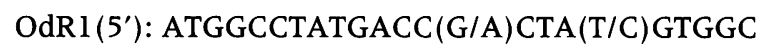

OdR2(3'): T(C/T/A)AG(G/A)CT(G/A)TAGATGAA

(G/A/C)GG(G/A)TTCAGC

$\operatorname{OdR3}\left(5^{\prime}\right): \mathrm{CT}(\mathrm{C} / \mathrm{G} / \mathrm{A}) \operatorname{CACAC}(\mathrm{A} / \mathrm{C}) \operatorname{CCCATGTA}(\mathrm{C} / \mathrm{T})$

$\mathrm{TT}(\mathrm{G} / \mathrm{T} / \mathrm{C}) \mathrm{TT}(\mathrm{C} / \mathrm{T})$

OdR4(3'): AG(G/A)TG(G/A)GAA(G/C)CG(A/G)CAG

$$
\text { GT(G/T/A) }
$$

PCR reactions were analyzed by agarose gel electrophoresis. Reamplified PCR products were digested with the restriction enzymes EcoRI, AvaII and AluI. The original products and digestion fragments were compared on agarose gels.

\section{Odorant Receptor Antibody Preparation}

Two peptide sequences were synthesized which contained motifs expressed in all members of the putative odorant receptor family. The first peptide designated ODl is LHTPMY(F/L)FLSNLSFC and represents a highly conserved portion of the second transmembrane domain of all known odorant receptors. The second peptide sequence (OD2), ARLSFCEDNVI(N/D)HFFC, is less highly conserved across the entire family of receptors 
but is highly conserved among several of the subfamilies identified. The sequence corresponds to an extracellular loop between transmembrane regions 4 and 5 of the odorant receptor family.

Peptides were chemically cross-linked to the carrier bovine serum albumin (BSA) for immunization into New Zealand white rabits according to established protocols (Hazelton Labs). Successive bleeds were tested and those positive for putative odorant receptors in olfactory cilia were isolated by purifying IgG on a Protein A-Sepharose column (Pharmacia). Eluates were further purified by adsorbing anti-BSA antibodies with two passes over a BSA-Sepharose column (Pharmacia). The subsequent eluate was spectrophotometrically assessed for protein (IgG) concentration and used for Western blot analysis and immunohistochemistry. The purified antibodies specifically stain olfactory neuronal cell bodies and sensory cilia in cross sections of olfactory epithelium. Control conditions were established by first incubating IgG with a 10 -fold excess $(w / w)$ of pure peptide.

\section{Western Blotting}

Crude membrane fractions were prepared from adult rat testis, brain, lung, ovary, heart, and kidney by homogenizing tissue in a Brinkmann Polytron in $5 \mathrm{ml}$ of ice cold $50 \mathrm{mM}$ Tris $\mathrm{pH} 7.4$ containing $0.1 \%$ Triton X-100, 1 mM EDTA and protease inhibitors $(4 \mu \mathrm{g} / \mathrm{ml}$ leupeptin, $2 \mu \mathrm{g} / \mathrm{ml}$ antipain, $2 \mu \mathrm{g} / \mathrm{ml}$ chymotrypsin, $2 \mu \mathrm{g} / \mathrm{ml}$ pepstatin), followed by centrifugation at $30,000 \times g$ for $20 \mathrm{~min}$ at $4 \mathrm{C}$. The supernatants were discarded and pellets resuspended in homogenization buffer. Cilia were prepared from male rats according to established procedures (20). Rat and hamster sperm were collected by suspending the cauda epididymis in a culture dish containing PBS. The epididymal tubules were carefully punctured under a dissecting microscope with a 27-gauge needle and sperm were allowed to disperse at room temperature with gentle shaking. Human sperm samples from normal, healthy donors were obtained from the Johns Hopkins Hospital Andrology Laboratory. Sperm were washed twice with PBS and the pelleted cells resuspended in the homogenization buffer described above. The cell suspensions were probe sonicated (Ultrasonics W-220F) on ice at $30 \%$ with two 5 -sec bursts. After spinning in a table top centrifuge at maximal speed, the supernatants were removed and the pellets resuspended in homogenization buffer. All tissue samples were protein assayed using DC protein assay reagants (Bio$\mathrm{rad})$. Protein samples $(50 \mu \mathrm{g})$ were subjected to electrophoresis using precast $8-16 \%$ gradient tris-glycine gels (Novex) for odorant receptor blotting and precast $12 \%$ tris-glycine gels (Novex) for GRK3 and $\beta$-arrestin 2 blotting. The separated proteins were semi-dry transferred to nitrocellulose and the blots blocked in 5\% nonfat dry milk (NFDM) for 2 hrs, followed by overnight incubation at $4^{\circ} \mathrm{C}$ in antibody diluted with $3 \%$ BSA/PBS. Antibody dilutions were 1:500 for OD1 and OD2. Antibodies to GRK3 and $\beta$-arrestin2 have been described previously $(13,21)$ and were diluted 1:100. The blots were developed using the ECL detection system (Amersham) according to the manufacturer's protocol or by the alkaline phosphatase method. For alkaline phosphatase detection, the blots were washed in $0.1 \%$ Tween-20 in PBS $3 \times 5 \mathrm{~min}$ and incubated for $1 \mathrm{hr}$ with alkaline phosphatase-conjugated goat anti-rabbit IgG secondary antibody (Boehringer Mannheim) in $1 \% \mathrm{BSA} / 1 \%$ NFDM. The strips were subsequently washed again as above and incubated for $5 \mathrm{~min}$ in the dark with BCIP/ NBT (GIBCO-BRL) in alkaline phosphatase substrate buffer $(0.1 \mathrm{M}$ Tris $\mathrm{pH} 9.5,0.1 \mathrm{M} \mathrm{NaCl}, 50$ $\mathrm{mM} \mathrm{MgCl}$ ).

\section{Immunohistochemistry and Indirect Immunofluorescence}

Adult Sprague-Dawley rats were used to obtain testis sections for immunohistochemical studies. Tissue sections were prepared and immunohistochemistry performed according to established procedures (14). Primary antibody dilutions were $1: 250$ for the odorant receptor antibodies and 1:50 for the GRK3 and $\beta$-arrestin 2 antibodies. The sections were stained with an avidinbiotin-peroxidase system (Vector Laboratories) using diaminobenzidine as the chromagen.

For indirect immunofluorescence microscopy of sperm, cells were harvested from the cauda epididymis as described above and dispersed in PBS. Sperm were then mixed with an equal volume of $8 \%$ freshly depolymerized paraformaldehyde and incubated on ice for 30 min. Subsequently, fixed sperm were wetmounted on slides and allowed to air dry. The slides were then washed in PBS for $3 \times 5 \mathrm{~min}, 50$ $\mathrm{mM} \mathrm{NH}_{4} \mathrm{Cl}$ for $3 \times 15 \mathrm{~min}$, PBS for $3 \times 5 \mathrm{~min}$, permeabilized in $0.1 \%$ Triton $X-100$ for $15 \mathrm{~min}$, and then rinsed again in PBS for $3 \times 5$ min. Slides were then blocked for $1 \mathrm{hr}$ at room temperature with $2 \% \mathrm{NGS} / 1 \% \mathrm{BSA}$ in PBS, suctioned dry, 
and incubated overnight at $4^{\circ} \mathrm{C}$ with antibody diluted in $0.5 \%$ BSA/PBS. Odorant receptor antibodies were diluted 1:250 and GRK3 and $\beta$ arrestin2 antibodies were diluted 1:50. Slides were washed in PBS for $3 \times 5 \mathrm{~min}$, incubated for $\mathrm{l} \mathrm{hr}$ at room temperature with $30 \mu \mathrm{g} / \mathrm{ml}$ FITCconjugated goat anti-rabbit IgG secondary antibody (Boehringer Mannheim), washed again in PBS for $3 \times 5$ minutes, coverslipped with vectashield mounting medium (Vector laboratories), and examined by immunofluorescence and confocal microscopy.

\section{RESULTS}

\section{Identification of an Odorant Receptor Multigene Family in Rat Testis}

We conducted RT-PCR using two pairs of degenerate primers directed against sequences conserved across known members of the odorant receptor family (Figure 1A). Using OdRl and OdR2, a discrete band is apparent in testis that corresponds in size to a band derived from a known odorant receptor clone, F2 (2). Because odorant receptor genes lack introns, controls were performed for each PCR reaction using RNA that was mock reverse transcribed in the absence of reverse transcriptase. No signal is detected in the testis control. Because mature sperm do not express mRNA, we focused on identifying receptors in those cells that are immediate precursors of mature, differentiated spermatids. We purified round spermatids from testis by elutriation and isolated RNA for RTPCR. A robust PCR product is observed in round spermatids using the OdR1 and OdR2 primers. No signal is detected in the spermatid control or in brain tissue. Primers OdR3 and OdR4 also produce a band of the correct size in round spermatids (Fig. 1A).

Buck and Axel (2) first obtained evidence for the existence of an odorant receptor multigene family by digesting PCR products with restriction enzymes and demonstrating that the sum of the digestion fragment sizes exceeded the molecular weight of the original PCR product. Utilizing three different restriction enzymes, we digested the PCR products derived from OdR1 and OdR2 in testis and OdR3 and OdR4 in round spermatids (Fig. 1B). In both cases, multiple products are generated whose sum exceeds the molecular weight of the parent band. Subcloning and sequencing of the PCR products confirm the pres-
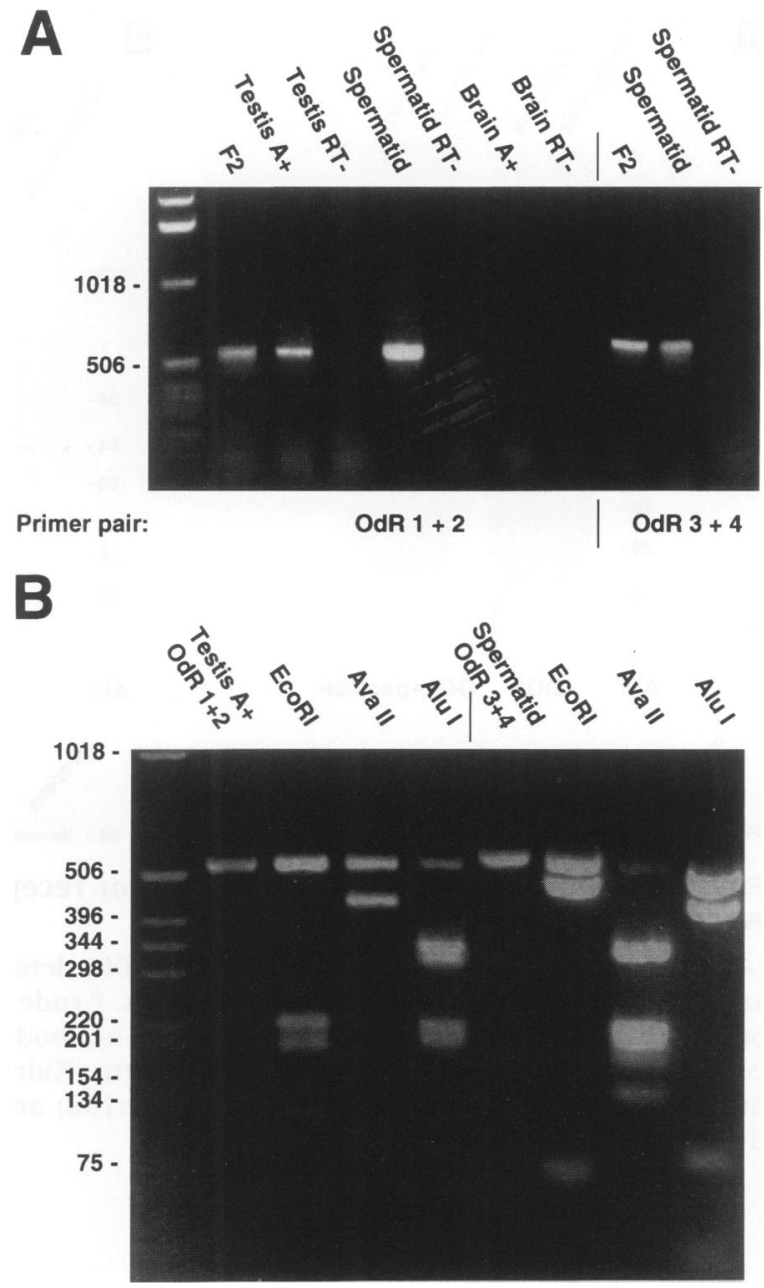

FIG. 1. RT-PCR amplification and restriction digestion of odorant receptor transcripts from rat testis and round spermatids

PCR was conducted with cDNA from rat testis, round spermatids, and brain using degenerate primers designed against conserved regions of all members of the originally cloned putative odorant receptor family. (A) Using OdRl and OdR2 primers, discrete products were obtained in testis and spermatids that correspond in size to a band derived from known odorant receptor clone F2. Primers OdR3 and OdR4 additionally produced a band in round spermatids corresponding in size to that obtained from the F2 clone. No products were detected in brain or in control samples that were reverse transcribed in the absence of reverse transcriptase. (B) The OdR $1+2$ testis product and the OdR $3+4$ spermatid product were isolated, reamplified and digested with EcoRI, AvaII, and AluI. In each case, fragments were produced whose sum was greater than that of the undigested band, suggesting the existence of multiple receptor transcripts in testis and round spermatids. 


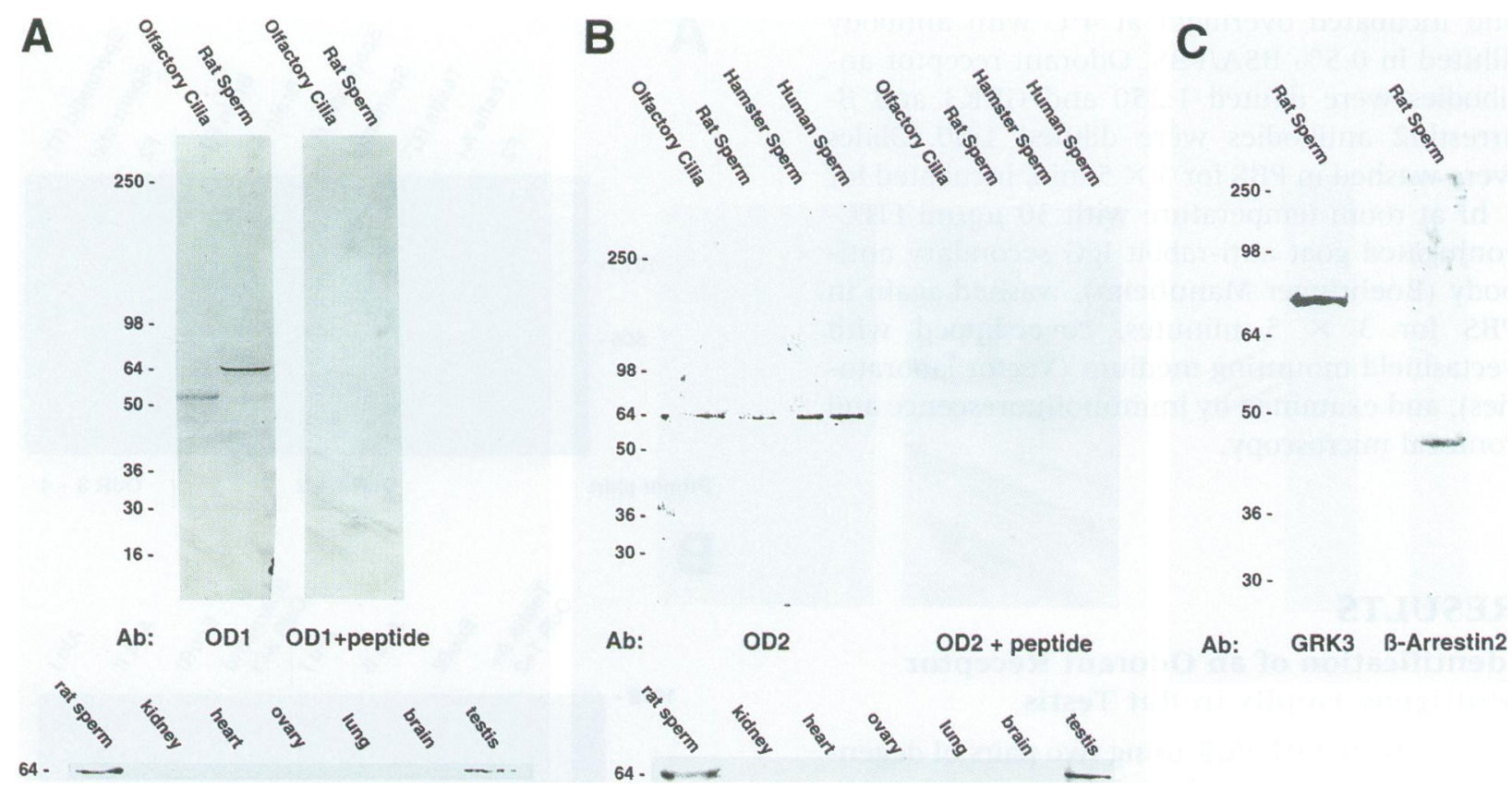

FIG. 2. Identification of putative odorant receptors, GRK3, and $\beta$-arrestin2 in mammalian sperm by Western blotting

(A) Anti-odorant receptor antibody ODl (1:500) detects specific bands of approximately $52 \mathrm{kD}$ in olfactory cilia and $64 \mathrm{kD}$ in testis and rat sperm membranes. Crude membranes prepared from kidney, heart, ovary, lung, and brain are negative. (B) Anti-odorant receptor antibody OD2 (1:500) recognizes a specific 64-kD band in olfactory cilia, testis, and rat, hamster, and human sperm. Kidney, heart, ovary, lung, and brain are negative. (C) Affinitypurified fusion protein antibodies to GRK3 (1:100) and $\beta$-arrestin2 (1:100) detect 77-kD and 45-kD bands, respectively, in rat sperm cytosolic extracts.

ence of several molecular species that share motifs with other members of the putative odorant receptor family (data not shown). These data are consistent with the existence of multiple odorant receptor transcripts in testis and more specifically in round spermatids.

\section{Immunodetection of Odorant Receptors, GRK3, and $\beta$-Arrestin2 in Sperm}

To document the presence of odorant receptor protein in sperm, we employed two different antibodies developed against conserved regions of known odorant receptors. Using antibody OD 1, we observe a band of approximately $52 \mathrm{kD}$ in olfactory cilia and a discrete band of approximately $64 \mathrm{kD}$ in rat sperm membranes (Fig. 2A). Both bands are abolished by preadsorption with the immunizing peptide. No specific immunore- active bands are observed in kidney, heart, ovary, lung, or brain (Fig. 2A).

Antibody OD2 detects a $64-\mathrm{kD}$ band in olfactory cilia and in rat, hamster, and human sperm membranes (Fig. 2B). Preadsorption with the immunizing peptide blocks the appearance of the 64-kD band. No specific immunoreactive bands are evident in kidney, heart, ovary, lung, or brain (Fig. 2B).

Breer and colleagues developed antibodies to specific odorant receptors which detect a $50-\mathrm{kD}$ band in olfactory cilia preparations (22). Upon deglycosylation with $\mathrm{N}$-glycosidase $\mathrm{F}$, the band shifts to $30-35 \mathrm{kD}$, consistent with the predicted molecular weight from molecular cloning studies. Western blotting of olfactory cilia using higher concentrations of antibody ODI reveals several specific bands between 50 and $64 \mathrm{kD}$ (data not shown). Taken together, these data 
suggest that differential post-translational modifications in sperm and cilia, such as glycosylation and phosphorylation, may account for the variation in molecular weight and their deviation from predicted molecular weight.

Western blot analysis of cauda sperm cytosolic extracts with specific antibodies to GRK3 and $\beta$-arrestin 2 reveals discrete bands of $77 \mathrm{kD}$ and $45 \mathrm{kD}$, respectively (Fig. $2 \mathrm{C}$ ). These antibodies previously identified GRK3 and $\beta$-arrestin2 proteins in testis and olfactory cilia (14). Thus, both sperm cells and olfactory cilia express similar isoforms of GRK and $\beta$-arrestin.

\section{Localization of Odorant Receptors, GRK3, and $\beta$-Arrestin 2 in Testis and Sperm}

Using immunohistochemistry, we colocalized putative odorant receptors, GRK3 and $\beta$-arrestin2 proteins in the adult rat testis (Fig. $3 \mathrm{~B}-\mathrm{F}$ ). The cellular composition of the seminiferous tubules varies along the length of the tubule according to the 14-stage growth cycle of the seminiferous epithelium (23). Thus, different cross-sectional segments of seminiferous tubule in rat testis correspond to distinct stages of spermatogenesis. Robust staining for odorant receptors, GRK3, and $\beta$-arrestin2 is apparent in adluminal cells of those seminiferous tubule segments undergoing spermatid elongation. Positive immunoreactivity is seen only in late spermatids, whereas spermatogonia, spermatocytes, early spermatids, Sertoli cells, and Leydig cells are negative (Fig. 3 B-F).

Immunofluorescent staining of cauda sperm with OD1 (data not shown) and OD2 antibodies (Fig. 4B) localizes receptor protein to the midpiece of the sperm tail. Confocal microscopy reveals punctate staining along the plasma membrane of the midpiece (Fig. 4 C-E). A particularly high density of receptors is detected on the connecting piece using the OD2 antibody. Immunofluorescent staining with this antibody is maintained when indirect immunofluorescence is performed on unpermeabilized, intact sperm. This is consistent with antibody recognition of an extracellular epitope. GRK3 and $\beta$-arrestin 2 immunoreactivity occurs throughout the midpiece, with higher densities in the proximal midpiece immediately subjacent to the connecting piece (Fig. $5 \mathrm{~A}$ and B). For all three proteins studied, no staining is present in the sperm head, the principal piece or the endpiece (Figs. 4 and 5).

\section{DISCUSSION}

The main finding of our study is the selective localizations of putative odorant receptors and associated desensitizing proteins in mature sperm cells. The proteins colocalize by indirect immunofluorescence in the midpiece. Whereas Western blotting identifies putative odorant receptors in the membrane fraction, GRK3 and $\beta$-arrestin 2 are identified in cytosolic extracts. The midpiece is that part of the sperm tail characterized by the presence of tightly packed mitochondria, and therefore contributes to the production of energy required for motility (24). Chemotaxis of sperm in invertebrates is associated with marked augmentation of respiratory activity, presumably to maximize locomotion toward the egg $(4,5)$. In mammals, a large portion of ejaculated sperm are retained motionless in the female reproductive tract; upon ovulation, an unidentified signal stimulates sperm motility, rapidly propelling sperm toward the fertilization site (25). It is plausible that ovulation triggers the release of an agent that is specifically recognized by odorant receptor proteins, resulting in a respiratory burst and locomotion toward the egg.

Desensitization occurs in essentially all interactions between ligands and G-protein coupled receptors. The association of GRK3 and $\beta$-arrestin2 with putative odorant receptors in rat sperm implies a role for desensitization in mammalian sperm-egg communication. In sea urchin sperm, "egg-derived" peptides produce a surge in cGMP levels followed by a rapid decline within seconds (26). Exposure of A. Punctulata sperm membranes to elevated concentrations of resact results in dephosphorylation and subsequent inactivation of the membrane guanylate cyclase, possibly representing an adaptive response in invertebrates to sustained receptor occupancy $(15,16,27)$. Agonist-induced desensitization may be particularly important in mammalian fertilization as a means of regulating sperm locomotion once the egg has been reached. It is striking that similar isoforms of GRK and $\beta$-arrestin are detected in association with odorant receptors in both olfactory cilia and sperm cells, emphasizing the potential similarities between olfactory and spermatozoal signal transduction systems.

In permeabilized preparations of olfactory cilia, odorants stimulate cAMP and/or $\mathrm{IP}_{3}$ production (28). Do these second messenger systems participate in sperm activation following stimulation of putative odorant receptors? Sperm capacitation in the female reproductive 

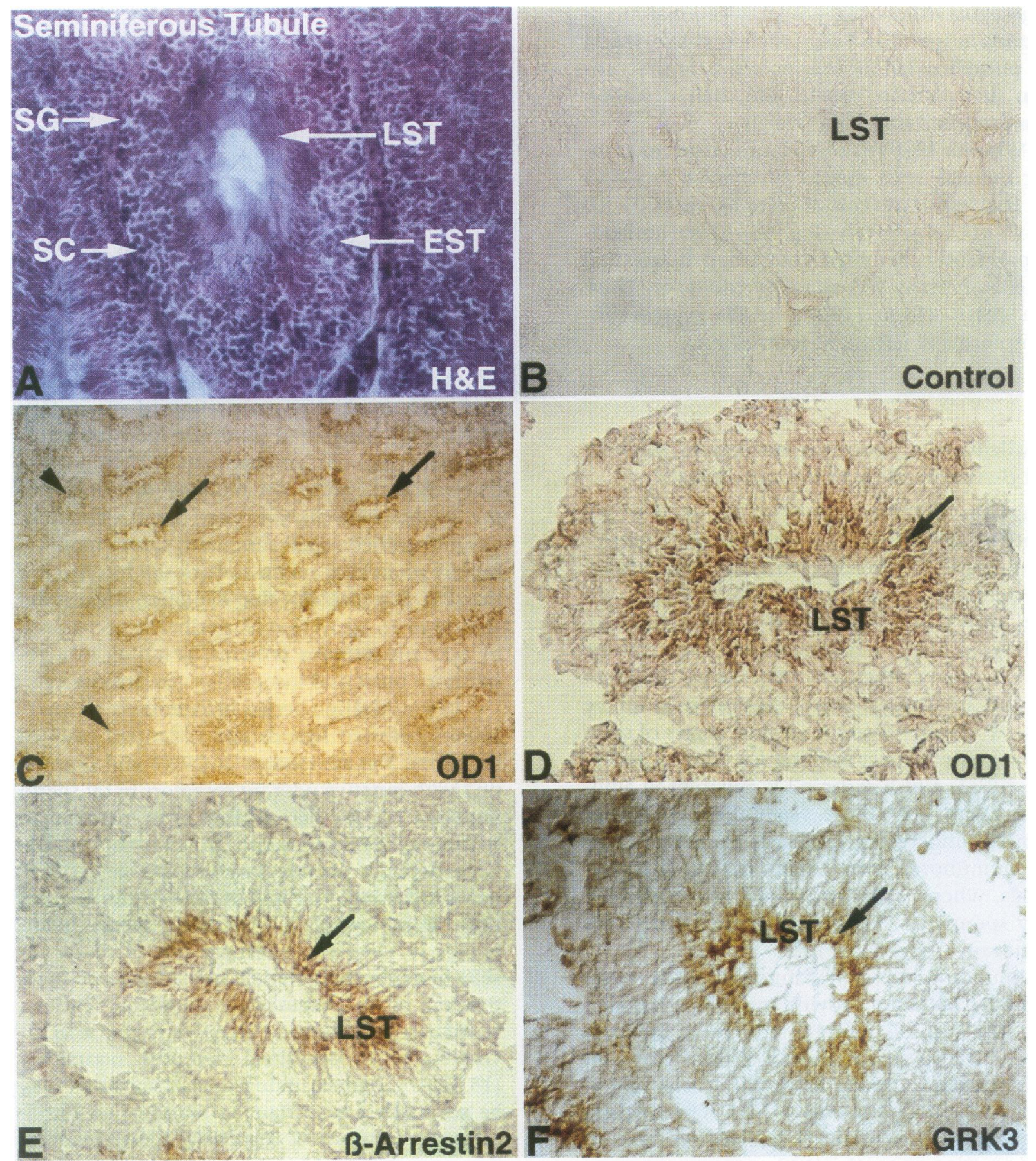

FIG. 3. Putative odorant receptors, GRK3, and $\beta$-arrestin2 colocalize in late spermatids of rat testis by immunohistochemistry

(A) A hematoxylin and eosin (HEE) stain of the rat testis reveals seminiferous tubule cross sections representing each of the 14 stages of the epithelial cycle. Shown here is a tubule cross section that contains cells representative of the differentiation continuum including spermatogonia (SG), spermatocyte (SC), early spermatid (EST), and late spermatid (LST); 200×. (B) Preincubation of the ODl antibody with pure peptide produced no staining of the testis; $200 \times$. (C) The seminiferous tubule cross sections containing elongating spermatids stain intensely with the ODl antibody (arrows), while tubules at earlier stages in the spermatogenic cycle are negative (arrowheads); $100 \times$. (D) The OD1 antibody (1:250) stains adluminal late spermatids; $200 \times$. (E and F) $\beta$-Arrestin 2 and GRK3 antibodies (1:50) similarly stain late spermatids; $200 \times$. The antibodies do not stain spermatogonia, spermatocytes, early spermatids, Sertoli cells, or Leydig cells. 

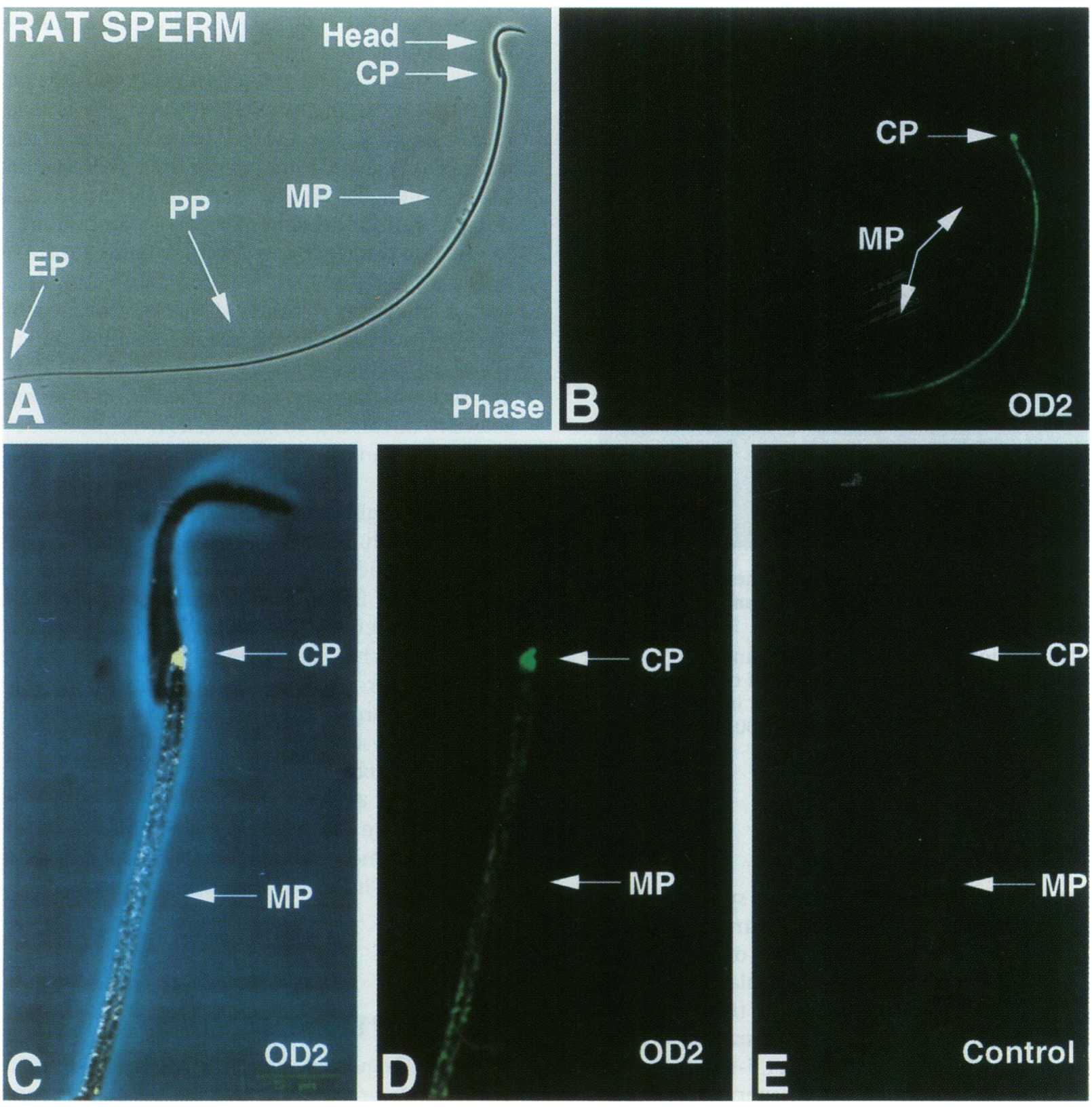

FIG. 4. Indirect immunofluorescent staining of mature rat sperm with odorant receptor antibodies

(A) A phase image of a rat sperm isolated from the cauda epididymis demonstrates its anatomical features including head, connecting piece (CP), midpiece (MP), principal piece (PP), and endpiece (EP); 1000×. (B) Indirect immunofluorescent staining with the OD2 antibody (1:200) illuminates the connecting piece and midpiece of mature sperm. The head, principal piece, and endpiece are negative; 1000×. (C) Indirect immunofluorescent confocal microscopy of positively stained rat sperm overlayed on the corresponding phase image reveals intense staining of the connecting piece and diffuse punctate staining along the plasma membrane of the midpiece; Bar $=5 \mu \mathrm{m}$. The fluorescent staining pattern (D) is completely blocked when antibody is preadsorbed with pure peptide (E). 


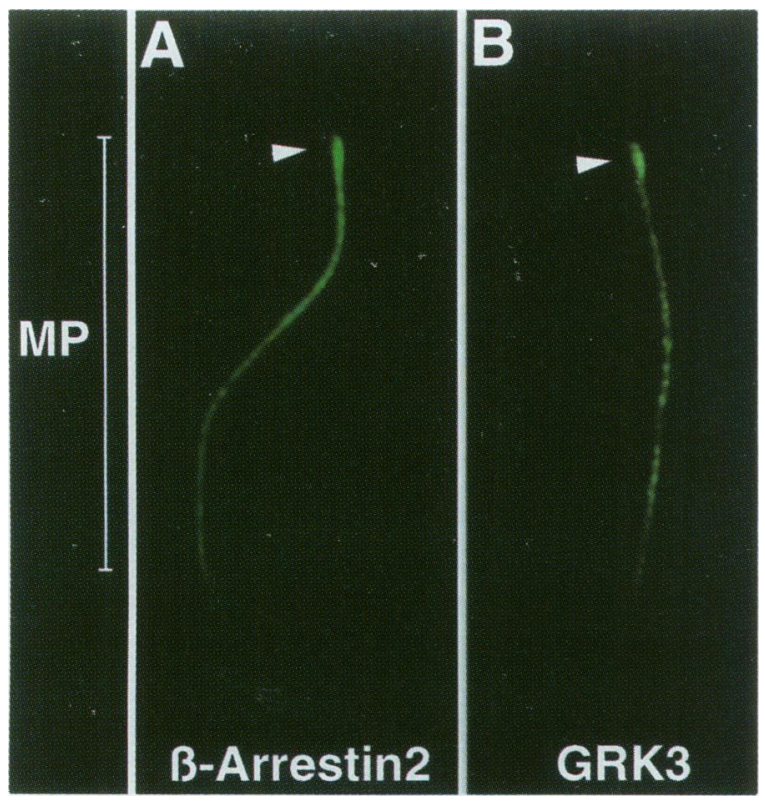

FIG. 5. Indirect immunofluorescent staining of mature rat sperm with GRK3 and $\beta$-arrestin2 antibodies

Antibodies to $\beta$-arrestin2 (1:50) (A) and GRK3 (1:50) (B) stain the midpiece (MP) of cauda sperm. Staining with both antibodies is most intense at the proximal midpiece (arrowheads); 1000×.

tract involves alterations in the sperm surface coat, resulting in exposure of surface proteins (31). Subsequent hyperactivation of sperm coincides with elevations in intracellular cAMP, $\mathrm{pH}$, and calcium (32). Alterations in the phosphoinositide system have not been characterized. We recently identified inositol 1,4,5-trisphosphate $\left(\mathrm{IP}_{3}\right)$ receptors in mammalian sperm (Walensky and Snyder, in preparation) and immunohistochemically detected $\mathrm{IP}_{3}$ receptor in the proximal midpiece of rat sperm. In the present study, high densities of odorant receptor, GRK3, and $\beta$ arrestin2 staining are also observed in the vicinity of the proximal midpiece. Thus, the proximal midpiece of rat sperm may be a center for signal transduction activity that contributes to motility regulation (Fig. 6). During hyperactivation in hamster sperm there are increased levels of calcium in the midpiece, which correlate with changes in the flagellar beat amplitude and frequency (33). Putative chemotactic ligand-receptor interactions may produce an $\mathrm{IP}_{3}$-induced calcium release from an internal store at the proximal midpiece, which may in turn contrib- ute to elevated internal calcium and a subsequent change in motility.

Eisenbach and colleagues have proposed that chemotaxis in mammalian fertilization is distinctly suited to select those sperm that are in the optimal physiologic state at the time of ovulation (34). When Parmentier and colleagues conducted immunohistochemistry with an antibody to one dog testis odorant receptor named DTMT, only a limited population of dog sperm exhibited robust midpiece staining (17). The absence of staining in some cells may be the result of differential expression of diverse populations of odorant receptors among sperm, thereby conferring selective advantage to some cells over others depending upon the particular female environment.

What might be the nature of the ligand that interacts with putative odorant receptors? Appropriate candidate molecules are likely to be contained in follicular fluid, since this medium can attract sperm. (7) Isolation of the appropriate ligand and characterization of its interactions with receptors such as those identified in this study, may provide further insight into odorant receptor physiology and mammalian fertilization. Ultimately, dissecting the molecular components that underly chemoattractive processes in mammalian sperm could have implications for the development of diagnostic tests and new therapies for infertility and contraception.

\section{ACKNOWLEDGMENTS}

LDW is supported by NIH Medical Scientist Training Program Grant GM 07309; AJR is supported by USPHS Grant F32 DC00121-02; SHS is supported by USPHS Grant DA-00266 and Research Scientist Award DA-00074; and GVR is supported by a McKnight Scholars Award, a grant from the W. M. Keck Foundation, and the Whitehall Foundation, International Flavors and Fragrances, and USPHS Grant 1 R29 DC 0087201. The authors thank Dr. Osamu Matsuzaki and Robert Bakin for their assistance in antibody production and affinity purification, Dr. William Wright for assistance in spermatid purification and for critically reading the manuscript, Michael Delannoy for his expert technical guidance with confocal microscopy, and Dr. Thomas S. K. Chang, Noam Cohen, and David Sabatini for helpful discussions. 


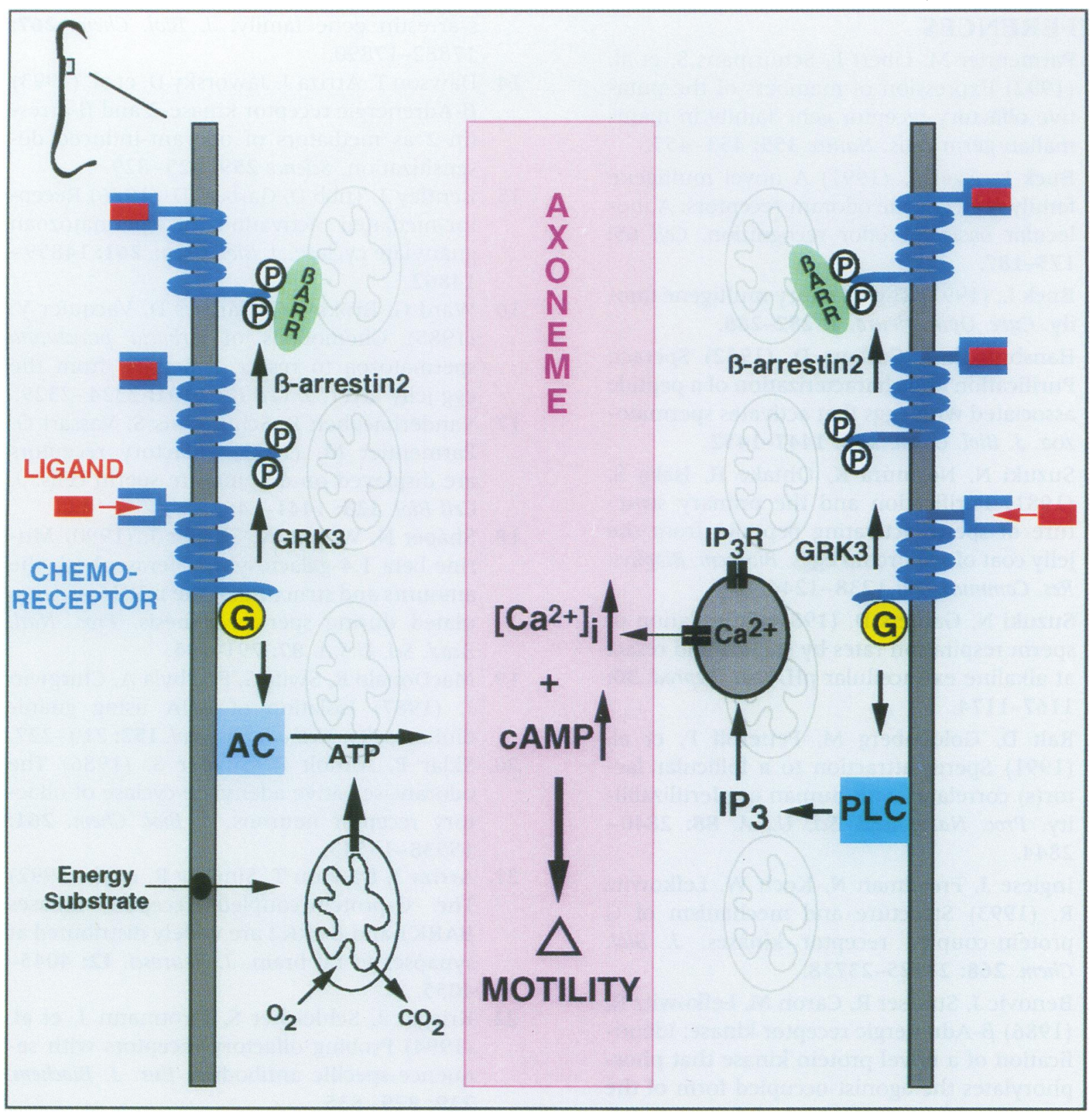

FIG. 6. Model of signalling events in mammalian sperm triggered by a chemotactic ligand produced by the egg

As in the olfactory system, putative sperm chemoreceptors may be coupled with either adenylate cyclase (AC) or phospholipase C (PLC) by the appropriate G protein (G). Stimulation of the receptor by a chemotactic ligand would result in conversion of cellular ATP to cAMP, which would in turn stimulate respiration and motility. In addition, activation of PLC would produce inositol 1,4,5-trisphosphate $\left(\mathrm{IP}_{3}\right)$ from phosphatidylinositol 4,5-bisphosphate $\left(\mathrm{PIP}_{2}\right) . \mathrm{IP}_{3}$-stimulation of $\mathrm{IP}_{3}$ receptors $\left(\mathrm{IP}_{3} \mathrm{R}\right)$ at the proximal midpiece would release calcium from stores in this region, thereby elevating intracellular calcium and modulating motility. Phosphorylation of agonist-occupied chemoreceptors by G-protein receptor kinase 3 (GRK3), followed by $\beta$-arrestin 2 ( $\beta$ ARR) binding, would subsequently desensitize the receptors. 


\section{REFERENCES}

1. Parmentier M, Libert F, Schurmans S, et al. (1992) Expression of members of the putative olfactory receptor gene family in mammalian germ cells. Nature 355: 453-455.

2. Buck L, Axel A. (1991) A novel multigene family may encode odorant receptors: A molecular basis for odor recognition. Cell 65: 175-187.

3. Buck L. (1992) The olfactory multigene family. Curr. Opin. Neuro. 2: 282-288.

4. Hansbrough J, Garbers D. (1982) Speract: Purification and characterization of a peptide associated with eggs that activates spermatozoa. J. Biol. Chem. 256: 1447-1452.

5. Suzuki N, Normura $K$, Ohtake $H$, Isaka S. (1981) Purification and the primary structure of sperm-activating peptides from the jelly coat of sea urchin eggs. Biochem. Biophys. Res. Commun. 99: 1238-1244.

6. Suzuki N, Garbers D. (1984) Stimulation of sperm respiration rates by speract and resact at alkaline extracellular pH. Biol. Reprod. 30: 1167-1174.

7. Ralt D, Goldenberg $M$, Fetterolf $P$, et al. (1991) Sperm attraction to a follicular factor(s) correlates with human egg fertilizability. Proc. Natl. Acad. Sci. U.S.A. 88: 28402844.

8. Inglese J, Freedman N, Koch W, Lefkowitz R. (1993) Structure and mechanism of G protein-coupled receptor kinases. J. Biol. Chem. 268: 23725-23738.

9. Benovic J, Strasser R, Caron M, Lefkowitz R. (1986) $\beta$-Adrenergic receptor kinase: Identification of a novel protein kinase that phosphorylates the agonist-occupied form of the receptor. Proc. Natl. Acad. Sci. U.S.A. 83: 2797-2801.

10. Benovic J, Mayor F, Staniszewski C, Lefkowitz R, Caron M. (1987) Purification and characterization of the $\beta$-adrenergic receptor kinase. J. Biol. Chem. 262: 9026-9032.

11. Lohse M, Benovic J, Codina J, Caron M, Lefkowitz R. (1990) $\beta$-Arrestin: A protein that regulates $\beta$-adrenergic receptor function. Science 248: 1547-1549.

12. Shinohara $T$, Dietzschold B, Craft $C$, et al. (1987) Primary and secondary structure of bovine retinal $\mathrm{S}$ antigen (48-kDa protein) Proc. Natl. Acad. Sci. U.S.A. 84: 6975-6979.

13. Attramadal H, Arriza J, Aoki C, et al. (1992) $\beta$-Arrestin2, a novel member of the arrestin/ s-arrestin gene family. J. Biol. Chem. 267: 17882-17890.

14. Dawson T, Arriza J, Jaworsky D, et al. (1993) $\beta$-Adrenergic receptor kinase- 2 and $\beta$-arrestin-2 as mediators of odorant-induced desensitization. Science 259: 825-829.

15. Bentley J, Tubb D, Garbers D. (1986) Receptor-mediated activation of spermatozoan guanylate cyclase. J. Biol. Chem. 261: 1485914862.

16. Ward G, Brokaw C, Garbers D, Vacquier V. (1985) Chemotaxis of Arbacia punctulata spermatozoa to resact, a peptide from the egg jelly layer. J. Cell Biol. 101: 2324-2329.

17. Vanderhaeghen $P$, Schurmans $S$, Vassart G, Parmentier M. (1993) Olfactory receptors are displayed on dog mature sperm cells. $J$. Cell Biol. 123: 1441-1452.

18. Shaper N, Wright W, Shaper J. (1990) Murine beta 1,4-galactosyltransferase: both the amounts and structure of the mRNA are regulated during spermatogenesis. Proc. Natl. Acad. Sci. U.S.A. 87: 791-795.

19. MacDonald R, Swift G, Przybyla A, Chirgwin J. (1987) Isolation of RNA using guanidinium salts. Methods Enzymol. 152: 219-227.

20. Sklar P, Anholt R, Snyder S. (1986) The odorant-sensitive adenylate cyclase of olfactory receptor neurons. J. Biol. Chem. 261: 15538-15543.

21. Arriza J, Dawson T, Simerly R, et al. (1992) The G-protein-coupled receptor kinases $\beta A R K 1$ and $\beta$ ARK2 are widely distributed at synapses in rat brain. J. Neurosci. 12: 40454055.

22. Krieger J, Schleicher S, Strotmann J, et al. (1994) Probing olfactory receptors with sequence-specific antibodies. Eur. J. Biochem. 219: 829-835.

23. Dym M, Clermont Y. (1970) Role of spermatogonia in the repair of the seminiferous epithelium following $\mathrm{x}$-irradition of the rat testis. Am. J. Anat. 18: 265-281.

24. Ford W, Rees J. (1990) The bioenergetics of mammalian sperm motility. In: Gagnon, C (ed). Controls of Sperm Motility: Biological and Clinical Apsects. CRC Press, Boca Raton.

25. Hunter R. (1987) Human fertilization in vivo, with special reference to progression, storage and release of competent spermatozoa. Hum. Reprod. 2: 329-332.

26. Hansbrough J, Garbers D. (1981) Sodiumdependent activation of sea urchin spermatozoa by speract and monensin. J. Biol. Chem. 256: 1447-1452. 
27. Bentley J, Shimomura H, Garbers D. (1986) Retention of a functional resact receptor in isolated sperm plasma membranes. Cell 45: 281-288.

28. Pace U, Hanski E, Saloman Y, Lancet D. (1985) Odorant-sensitive adenylate cyclase mediates olfactory reception. Nature 316: 225-258.

29. Breer H, Boekhoff I, Tareilus E. (1990) Rapid kinetics of second messenger formation in olfactory transduction. Nature 345: 65-68.

30. Ronnett G, Parfitt D, Hester L, Snyder S. (1991) Odorant-sensitive adenylate cylcase: Rapid potent activation and desensitization in primary olfactory neuronal cultures. Proc. Natl. Acad. Sci. U.S.A. 88: 2366-2369.

31. Suarez S, Pollard J. (1990) Capacitation, the

Contributed by S. H. Snyder on November 7, 1994. acrosome reaction, and motility in mammalian sperm. In: Gagnon C (ed). Controls of Sperm Moltility: Biological and Clinical Aspects. CRC Press, Boca Raton.

32. Lindemann C, Kanous K. (1989) Regulation of mammalian sperm motility. Arch. Androl. 23: 1-23.

33. Suarez S, Varosi S, Dai X. (1993) Intracellular calcium increases with hyperactivation in intact, moving hamster sperm and oscillates with the flagellar beat cycle. Proc. Natl. Acad. Sci. U.S.A. 90: 4660-4663.

34. Eisenbach M, Ralt D. (1992) Precontact mammalian sperm-egg communication and role in fertilization. Am. J. Physiol. 262: C1095-C1101. 